\title{
COMPARISON BETWEEN DECISION TREE AND OPTIMAL POWER FLOW TECHNIQUES APLIED TO VOLTAGE CORRECTIVE CONTROL IN ELECTRIC SYSTEMS
}

\author{
Joabe Chaves Nogueira ${ }^{1}$, Benedito da Graças Duarte Rodrigues ${ }^{2}$, Amanda Thais dos Reis \\ Fernandes $^{3}$, Werbeston Douglas de Oliveira ${ }^{4}$ and Ubiratan Holanda Bezerra ${ }^{5}$
}

\author{
${ }^{1,5}$ Institute of Techonology, Federal University of Pará - UFPA. Belém-Pará, Brazil. \\ ${ }^{2}$ Eletronorte. Belém-Pará, Brazil. \\ ${ }^{3,4}$ Federal University of Amapá - UNIFAP. Macapá-Amapá, Brazil.
}

Email: joabecn@gmail.com, benedito.rodrigues@eln.gov.br, amandathais1458@gmail.com, wdoliveira@unifap.br, bira@ufpa.br

Received: Jan $20^{\text {th }}, 2020$

Accepted: Jan $23^{\text {th }}, 2020$

Published: February $10^{\text {th }}, 2020$

Copyright (C2016 by authors and Galileo Institute of Technology and Education of the Amazon (ITEGAM).

This work is licensed under the Creative Commons Attribution International License (CC BY 4.0).

https://creativecommons.org/licen ses/by/4.0/



Opean Aceses:

\begin{abstract}
This article presents a comparison of using techniques of optimal load flow and decision tree in making corrective voltage control actions for electrical power systems under insecure operation condition, that is, with voltage constraints violated. The decision tree technique is used in conjunction with a technique of sensitivity analysis in such a way that control actions are taken to be more effective to eliminate the voltage constraints violation in each case of contingency analyzed. A comparison is made between the control actions suggested by the optimal load flow strategy and those suggested by the decision tree for the same operating condition, discussing the achievement of implementing these actions in a real power system. The analysis methodology proposed here is tested in a real power system of a Brazilian utility, which operates in the State of Amapá - Brazil. The results showed how both methodologies can be used as operational tools in power system supervision and control centers.
\end{abstract}

Keywords: Decision tree, data mining, optimal power flow, voltage sensitivity analysis, power systems.

\section{INTRODUCTION}

Electric Power Systems (EPS) are highly complex systems to operate mainly due to some aspects as the increasing power demand to be supplied with high power quality indicators; incorporation of massive distributed generation in the electric networks; and an increasingly participation of automation and data communication links to make the system more observable, controllable, secure, economic and efficient.

Static Security Assessment (SSA) is a main function that continuously tracks the EPS steady-state operation points aiming at detecting insecure operation conditions in order to support the adoption of preventive and corrective management actions to maintain the EPS integrity and operating in a secure region. In steady-state condition, a power system can be disturbed in several ways that can make it insecure, such as changes in grid topology, load variation, switching maneuvers of grid equipment, changes in generating machines operational points, and other severe disturbances that may cause serious damage to equipment, accidents, and disruption of power to large areas [1,2].

In situations of insecure operation, the system operator must identify which control measures needs to be taken to bring the system back to a secure operation region. At this moment, the experience in system operation is considered fundamental, because only with previous knowledge of the system under analysis, the operator can know which control variables will most influence the system in the return to secure operating points [3].

The present work proposes to use a methodology based on Decision Trees (DTs) as presented in [4], as an auxiliary tool for the application of corrective control measures in the operation of a real electrical power system in situation of contingency and insecure operational state. A comparative analysis of the corrective control actions suggested by the decision tree methodology and those obtained by the application of an Optimal Power Flow (OPF) procedure with objective function of voltage 
control, is made in order to verify the effectiveness and feasibility of the control actions proposed by both methodologies. The software FLUPOT [5] and ANAREDE [6] were used to form the database of electric power system operation points for training the DT structure as well as to calculate optimal power solutions for the EPS under analysis.

\section{II.1 ELECTRIC POWER SYSTEMS SECURITY ASSESSMENT}

Electric Power Systems can be disturbed by various causes, and when the system withstands these disturbances without violating operational limits, it is said the EPS operates in a secure state [7]. It is very important to predict the disturbance consequences and the ability to prevent deterioration in quality of service [8].

The analysis of EPS security covers static and dynamic analysis. Static Security Assessment (SSA) considers operating conditions such as overloads, under and over voltages, active and reactive power generation limits, among others using load flow calculation $[9,10]$. Dynamic Security Assessment (DSA) evaluates the system transient behavior after the occurrence of large disturbances, such as short circuit for example, so that it is of interest to determine if the system can operate maintaining a dynamically acceptable performance (transient stability) [11], and it is simulated considering dynamic time-varying models to represent the EPS, whose solution involves numerical integration algorithms that require great computational effort [12].

Implementing real-time security measures becomes dependent on observing the runtime of power flows and optimal power flow (OPF), but the larger the system, the greater the complexity and amount of data to be processed and interpreted. Considering these factors, data mining techniques applied to power systems stand out as a complementary action in the analysis of EPS due to their ability to extract useful information for the EPS operation from data sets, serving as an auxiliary tool for making decision on corrective controls [13].

An EPS may be subject to loading, operating and security restrictions. Load constraints are the active and reactive power injections specified on the load and generation buses using the load flow equations. Operating restrictions are specified for the bus voltage magnitude limits during operation, the power flow limits on the transmission lines and transformers, and the reactive power injections at generation buses. Under security restrictions, the system is subjected to a set of possible contingencies to characterize the EPS security margins in the case these contingencies happen $[3,4,14]$.

The SSA performed in this work subjects the system to contingencies such as loss of generation, load variation, disconnection of transmission lines and transformers, switching of capacitor banks and reactors, among others. In these situations, it is up to the operator to analyze which control measures to be employed in real time, depending on which operating state the system is in. The EPS operating states can be classified as: secure, alert, emergency and restorative [15].

In the secure state, also called normal-secure, three type of restrictions must be met, that is, loading, operation and security restrictions, this means that the system provides active and reactive power to the load demand and there is no violation of operating limits and none of the contingency conditions listed as possible will bring the system to an emergency state. In the normal-insecure state, load and operating restrictions are met, but not all security restrictions are met. The system supplies the demand, but one of the possible contingencies can move the system to an emergencystate.

The emergency-state is characterized by violation of operation restrictions, as voltage magnitude limits, loading conditions of transmission lines and transformers among others. In the restorative state, the emergency is eliminated by manual or automatic shutdown of system parts with command coming directly from the control and supervision center or by local devices. When the system is shifted from the emergency state to the restorative state, system integrity is sacrificed for the benefit of compliance with operating restrictions.

Real-time operating statuses data and operating restrictions from an EPS are passed on to operators through the Supervisory, Control, and Data Acquisition System (SCADA) to the operating centers. With this real data and power flow simulation data, the system can be viewed and better operated, increasing its reliability [14].

\section{II.2 POWER FLOW FORMULATION}

A real-time supervision and control system consists of partial systems, grouped into data acquisition, generation control, analysis and network control (security). Tools available at the supervision and control center include: power flow studies, security assessment, state estimation, and sensibility analysis among others [16].

The power flow calculation essentially consists of determining the electric network operating state using a static model to represent the electric network. The modeling for power flow calculation is done by a set of algebraic equations, representing the active and reactive power balances at each electric node, as presented in equations (1) and (2) respectively [3].

$$
\begin{gathered}
\mathrm{P}_{\mathrm{Gi}}-\mathrm{P}_{\mathrm{Ci}}-\mathrm{P}_{\mathrm{Ti}}=0 \\
\mathrm{Q}_{\mathrm{Gi}}-\mathrm{Q}_{\mathrm{Ci}}-\mathrm{Q}_{\mathrm{Ti}}=0
\end{gathered}
$$

Where,

"P" _"Gi" e "Q" _"Gi" are the active and reactive power generation at bus $\mathrm{i}$.

"P" _"Ci" e "Q" _"Ci" are the active and reactive consumed power by loads connected at bus $i$.

"P" _"Ti" e "Q" _"Ti" are the active and reactive power injections at bus $i$, that is, the power flowing from bus i to all buses connected to bus $i$.

Considering the electric network is modeled by its admittance matrix Ybus, than the active and reactive power injections at bus i can be represented as in (3) and (4) respectively [4].

$$
\begin{aligned}
\mathrm{P}_{\mathrm{Ti}} & =\mathrm{V}_{\mathrm{i}} \sum_{k=1}^{n} \mathrm{~V}_{\mathrm{k}}\left[\mathrm{G}_{\mathrm{ik}} \cos \left(\delta_{\mathrm{ik}}\right)+\mathrm{B}_{\mathrm{ik}} \sin \left(\delta_{\mathrm{ik}}\right)\right] \\
\mathrm{Q}_{\mathrm{T} \mathrm{i}} & =\mathrm{V}_{\mathrm{i}} \sum_{k=1}^{n} \mathrm{~V}_{\mathrm{k}}\left[\mathrm{G}_{\mathrm{ik}} \sin \left(\delta_{\mathrm{ik}}\right)-\mathrm{B}_{\mathrm{ik}} \cos \left(\delta_{\mathrm{ik}}\right)\right]
\end{aligned}
$$

Where,

$\mathrm{V} \_\mathrm{i}$ and $\mathrm{V} \_\mathrm{k}$ : voltage magnitudes at buses $\mathrm{i}$ and $\mathrm{k}$ respectively; $\delta$ ik: phase angles difference between voltages at buses $i$ and $k$, being $\delta_{-} \mathrm{i}$ and $\delta_{-} \mathrm{k}$ phase angles of voltages $\mathrm{V}_{-} \mathrm{i}$ and $\mathrm{V} \_\mathrm{k}$ respectively. 
The algorithm for simultaneous solution of equations (1) and (2), via Newton-Raphson method can be found in [18]. The use of conventional load flow algorithms can produce many viable and secure solutions to the problem in question. Adopting one or other solution is a decision that depends on the merit analysis of each solution, by the technical team responsible for the EPS planning/ operation.

However, in many situations, it is desired to obtain an optimal solution to the problem. In this case, equations (5) and (6) are solved in such a way that the solution obtained minimizes an objective function, also known as cost function. This scenario is solved by optimal load flow (OPF) algorithms [20], whose generic formulation is:

Minimize F(x)

Subjected to:

$$
\begin{array}{r}
G(x)=0 \\
H(x) \leq 0
\end{array}
$$

Where,

$\mathrm{F}(\mathrm{x})$ - is the cost function to be minimized;

$\mathrm{G}(\mathrm{x})$ - corresponds to the set of equations (3) and (4) of the conventional load flow;

$\mathrm{H}(\mathrm{x})$ - are inequality constraints imposed on the problem.

\section{PROPOSED METHODOLOGY}

As stated in the introduction section, two distinct procedures will be used to generate corrective control actions to return the EPS to a secure operational condition, when it is subjected to different types of contingencies. The first technique used is based on decision trees (DTs) which is a computational intelligence technique, and the second is optimal power flow (OPF), which is an analytical technique widely used for solving this type of problem.

The same contingency situations are simulated by the two proposed techniques and secure operation points are taken from both solutions and the results found in the corrective control applications are compared.

\section{III.1 DECISION TREE}

The decision tree classification is an extremely simple technique that requires no configuration parameters and generally has a good degree of assertiveness [17]. The purpose of this paper is to use this technique [4] by analyzing the corrective control actions suggested by the DT solution, observing operation factors such as decision time, number of control actions necessary to implement the suggested solution, visualization of operating limits, system response to corrective action, among other aspects.

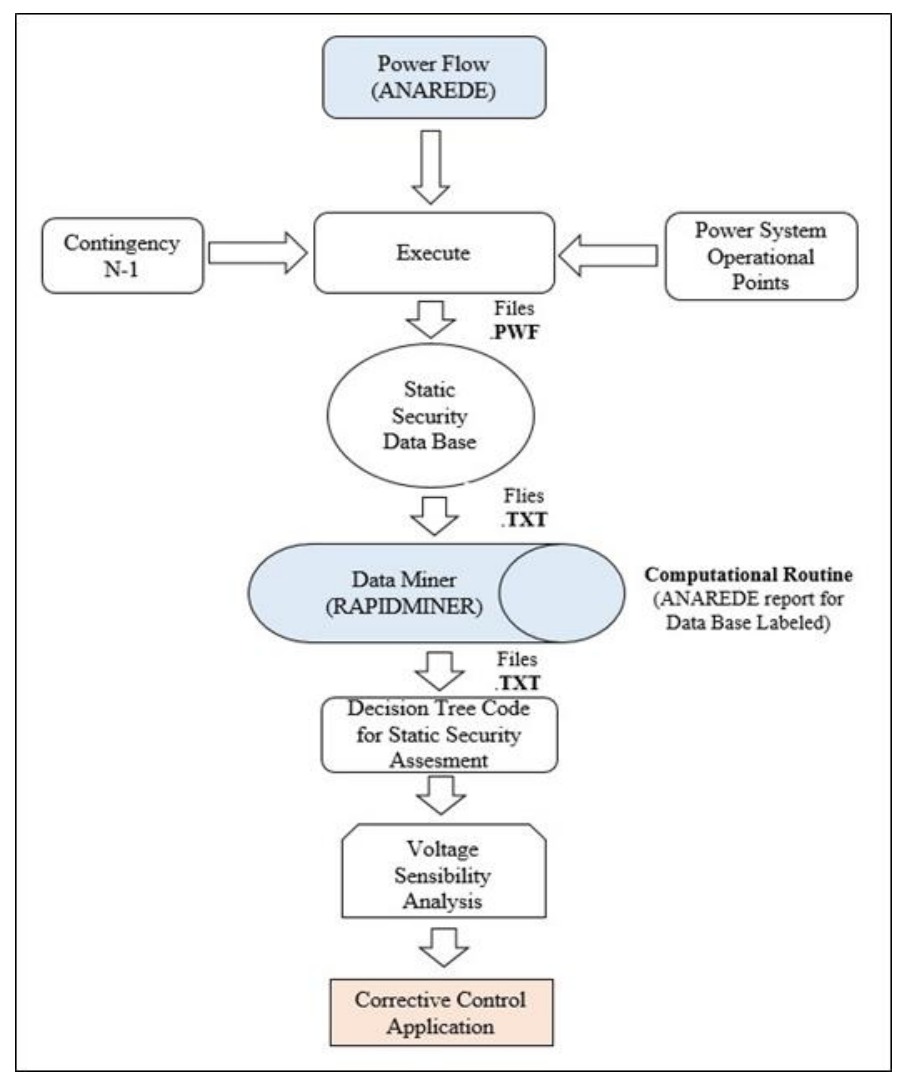

Figure 1: Flowchart of the proposed Decision Tree Methodology for EPS security assessment analysis. Source: Adapted from [4].

According to figure 1 , the steps for decision tree application on EPS corrective control are described as follows:

a) Using the ANAREDE software, a set of secure operating points are generated, following the EPS typical load curve profile, for the daily operating period; b) Again, using the ANAREDE software the secure operating points obtained in a) are subjected to a $(\mathrm{N}-1)$ contingency list, typical of the EPS operation such as, switching of transmission lines, transformers, capacitor banks, among others. The results of these simulations are files with PWF extension, and are labeled as secure or insecure, for the database formation to characterize the EPS static security under these operating conditions. 
c) Then this labeled database is subjected to a data mining step, via the RAPIDMINER software, in order to create the DT structure for the security classification of EPS operating points.

The generated DT will indicate, for each operational condition under contingency, which branches lead to a secure operation state. Following these branches, the operator may take the respective corrective control actions suggested by the DT in order to take the EPS back to a secure operating condition. At this point, a voltage sensitivity analysis is carried out.

\section{III.2 SENSITIVITY ANALYSIS}

Sensitivity analysis calculates the first order sensitivity factors, showing the behavior of certain electric grid quantities, called dependent variables, related to the variation of a control quantity, called the control variable.

Equations (3-4) could be rewritten in compact form as:

$$
\bar{g}(\bar{x}, \bar{u}, \bar{p})=0
$$

Where, $\bar{u}$ is the control variable vector, $\bar{x}$ is the controlled variable vector and $\bar{p}$ is the fixed parameters vector.

A perturbation in the vector of dependent variables $\bar{x}$ produced by changes introduced in the control variables $\bar{u}$ and the parameters $\bar{p}$ is given by the relation:

$$
\frac{\partial g}{\partial \bar{x}} \Delta \bar{x}+\frac{\partial g}{\partial \bar{u}} \Delta \bar{u}+\frac{\partial g}{\partial \bar{p}} \Delta \bar{p}=0
$$

Otherwise:

$$
\Delta \bar{x}=S_{u} \Delta \bar{u}+S_{p} \Delta \bar{p}
$$

With:

$$
S_{u}=-\left[\frac{\partial g}{\partial \bar{x}}\right]^{-1} \cdot \frac{\partial g}{\partial \bar{u}}
$$

and

$$
S_{p}==-\left[\frac{\partial g}{\partial \bar{x}}\right]^{-1} \cdot \frac{\partial g}{\partial \bar{p}}
$$

Matrices $S_{p}$ and $S_{u}$ are called sensitivity matrices and determine a relation between control and controlled variables.

This allows to estimate, although approximately, the behavior of electrical quantities as a function of changes made in some other system's variables and parameters.

In other words, the sensitivity analysis function can provide the operator with information on which control actions have the greatest effect on the voltage magnitude of a particular bus.

\section{III.3 OPTIMAL POWER FLOW}

Optimal Power Flow is considered an important tool that may improve the system reliability and quality, and aims to determine, among others, the best power distribution across the generating units in operation, the best voltage profile for the EPS, or even the best reactive power distribution, all based on optimizing a cost function (objective function) while meeting a constraint set, as presented in equations (5-6), [19, 20].
In the case studies to be presented in this article, the Flupot-CEPEL software was used as a tool for choosing corrective control actions to be adopted to guarantee a secure operation condition.

The objective function chosen in the optimization process is the voltage control, which is available as an option for users of FLUPOT, having as control variables active and reactive power generation, and reactive power injection in controlled voltage buses. According to the optimization method in [5], the algorithm determines a setting for the reactive controls in such a way as to keep voltage magnitudes at user's specified limits close to 1 pu.

The OPF procedure shown in figure 2 is based on the same operating point and the same $(\mathrm{N}-1)$ contingency list used to form the database in the decision tree procedure.

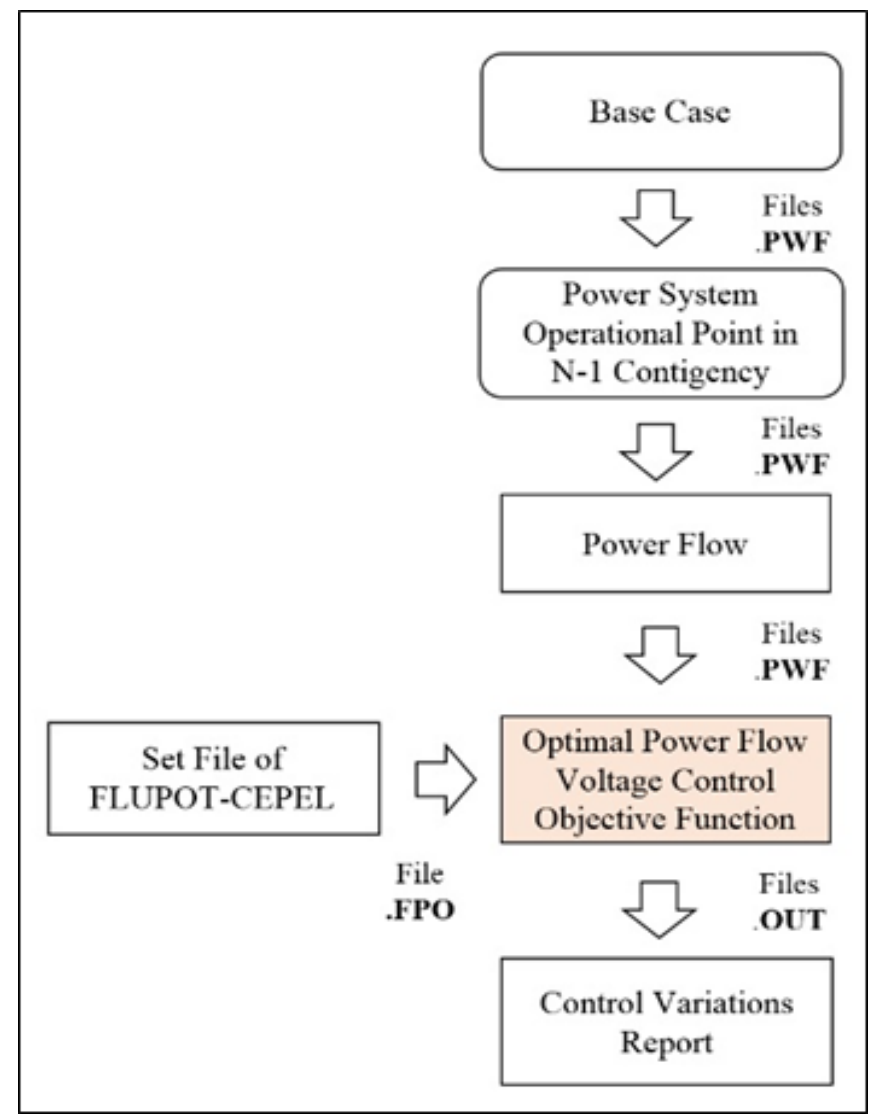

Figure 2: Flowchart of the methodology for obtaining corrective control actions via optimal power flow.

Source: Authors, (2019).

\section{RESULTS}

For a better understanding of the proposed methodology, it will be presented case studies on a real electric system, the Amapá Power System, located in the north region of Brazil, in the State of Amapá. In the simulations studies, the power flow by Newton-Raphson algorithm is used to obtain operating voltage values of the system under normal conditions and under contingencies.

Acceptable limits of bus voltage magnitudes for secure operation are between $0.95 \mathrm{pu}$ and $1.05 \mathrm{pu}$. The control strategies used have been performed to ensure that the system is operating within this secure voltage range.

The Amapá Electric System [4] is a hydrothermal EPS, having 51 buses, 12 equivalent generators, 32 power transformers and 17 transmission lines, operated by Eletrobrás-Eletronorte electric utility. This system is presented as a single-line diagram in figure 3 . 


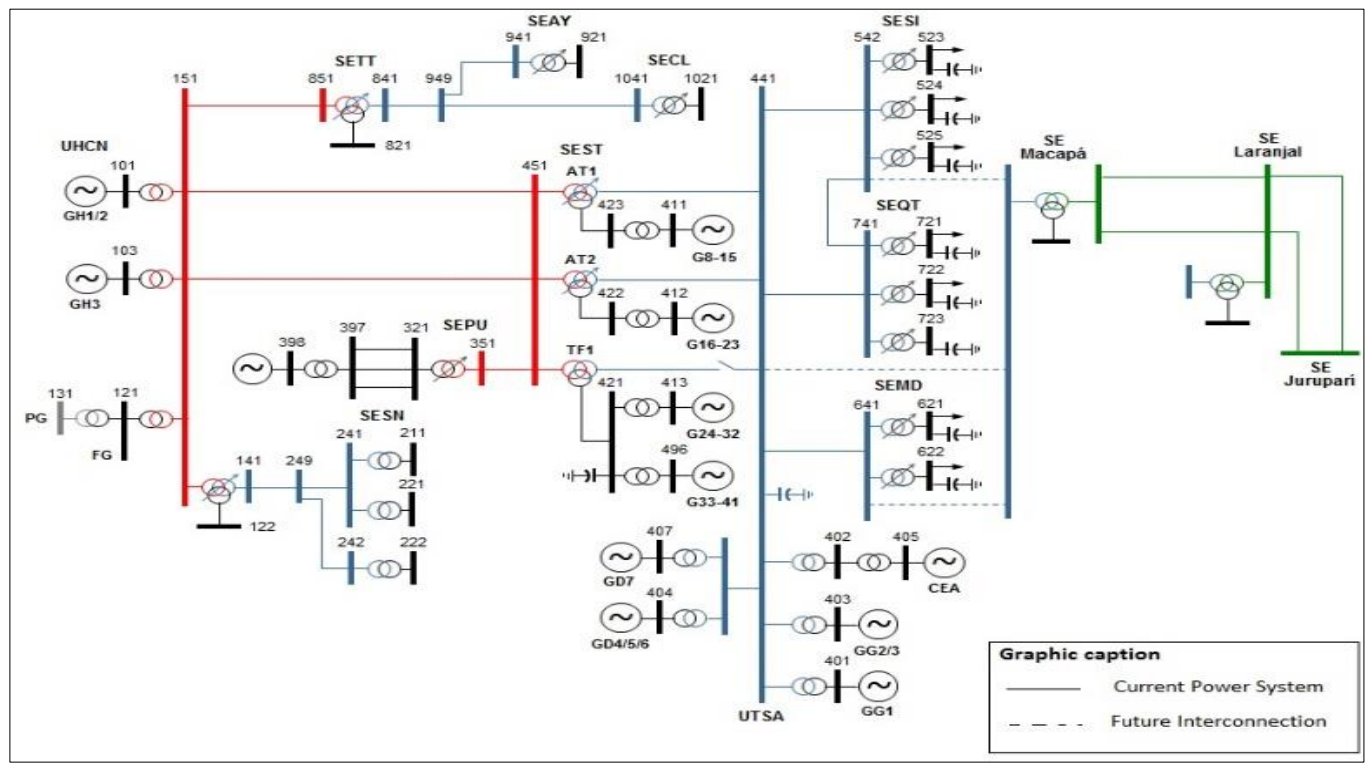

Figure 3: Amapá Power System single-line diagram.

Source: Adapted from [4].

The Amapá Electric System has predominant hydroelectric generation and is highly influenced by the availability of the Coaracy Nunes hydroelectric power plant (UHCN), whose power capacity is $78 \mathrm{MW}$. The Araguari River water flow indicates the full operation of this plant from January to September. Outside this period, the Santana thermoelectric plant (UTSA) starts operating to compose the generation base.

The Coaracy Nunes Hydroelectric Power Plant (UHCN) is connected to the Santana Thermoelectric Power Plant (UTSA) through two $138 \mathrm{kV}$ transmission lines (between buses 151 and 451).

\section{IV.1 CONTINGENCY 1: SHUTDOWN OF TRANSFORMER 722-741}

Considering a loading point taken from the database, the contingency was simulated which generated a decision tree as is shown in figure 3 , demonstrating two decision paths to bring the EPS to a safe operating condition (secure).

To establish corrective system control actions for this contingency, these two possible paths will be considered.

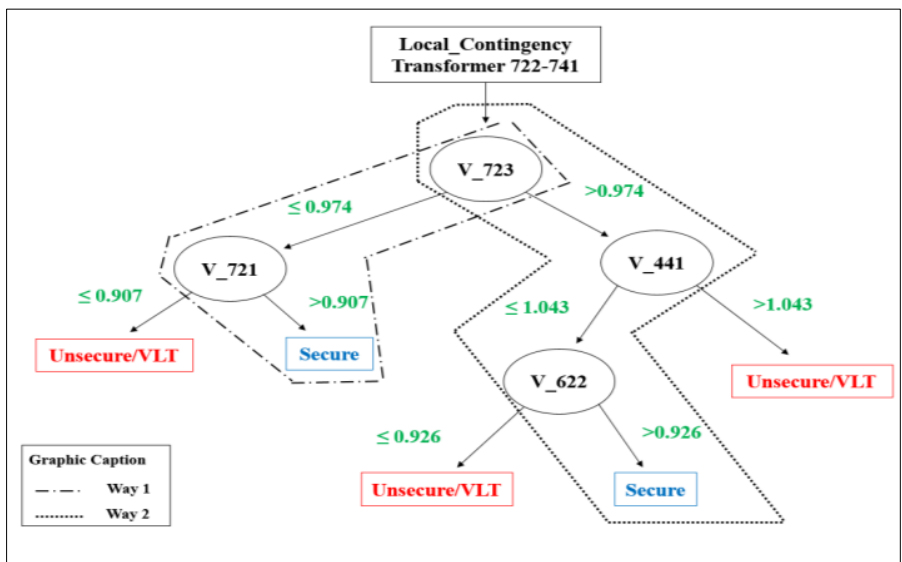

Figure 4: Decision tree generated for Contingency TR 722-741. Source: Authors, (2019).

The critical attributes of this decision tree are voltage magnitudes at buses 723, 441, 622 and 721. All of these specified buses have capacitor banks connected to them for local voltage control.

With the application of this contingency, the load flow solution indicated 10 buses with the upper limit of voltage magnitude violated. Sensitivity factors were calculated for the buses discriminated in the decision tree paths, namely buses 723 , 441, 622 and 721 which are the dependent variables, being the reactive generation and transformers' taps considered as control variables.

Usually, in a power system with over voltages, the priority of corrective control actions follows the order: capacitor banks switching, change in transformer Taps, and voltage set point changes in generation buses. Following this principle, a sensitivity analysis was conducted to buses $723,441,622$ and 721 in order to determine for which sources of reactive power these voltages magnitudes are more sensitive

Table 1 presents the results of this sensitivity analysis in relation to buses that have reactive power control, namely buses 404-101 and the transformers' taps. It is indicated a possible reactive control by bus 404 that can change the voltages of all buses specified in AD and influence the system as a whole.

Table 1: Voltage Sensibility Factors for Contingency TR 722741.

\begin{tabular}{|c|c|c|c|c|}
\hline \multirow{2}{*}{$\begin{array}{c}\text { Dependent } \\
\text { Variable }\end{array}$} & \multicolumn{4}{|c|}{ Control Variable } \\
\hline Bus Voltage \\
$\begin{array}{c}\text { Specified by } \\
\text { Decision Tree }\end{array}$ & $\begin{array}{c}\text { Bus } \\
\text { Number }\end{array}$ & $\begin{array}{c}\text { Sensitivity } \\
\text { Factor }\end{array}$ & Taps & $\begin{array}{c}\text { Sensitivit } \\
\text { y Factor }\end{array}$ \\
\cline { 3 - 4 } & 404 & 0,587 & $723 / 741$ & 1,256 \\
\cline { 2 - 4 } & 101 & 0,199 & $441 / 497$ & 0,345 \\
\hline V_723 & 404 & 0,529 & $441 / 497$ & 0,311 \\
\cline { 2 - 5 } & 101 & 0,179 & $441 / 498$ & 0,308 \\
\hline V_622 & 404 & 0,615 & $622 / 641$ & 1,092 \\
\cline { 2 - 4 } & 101 & 0,208 & $441 / 497$ & 0,961 \\
\hline V_721 & 404 & 0,634 & $721 / 741$ & 1,201 \\
\cline { 2 - 4 } & 101 & 0,214 & $441 / 497$ & 0,373 \\
\hline
\end{tabular}

Source: Authors, (2019). 
According to the DT indication and sensitivity analysis results, the voltage at bus 404 was set equal to $0.98 \mathrm{pu}$ and the capacitor bank at bus 723 was shutdown By applying this control action, the bus voltages are V723 $=1.027, \mathrm{~V} 441=1.042, \mathrm{~V} 622=$ 0.990 , and are within the limits of the decision tree way 2 , shown in figure 4.

Running an OPF for the same contingency 37 control actions are activated to bring the system to an optimal operating point, as shown in Table 2. It is observed that bus voltages are as close as possible to $1 \mathrm{pu}$. Thereby, from an operating point of view, it is difficult to execute all these controls real time in a short time period and reach this operational state.

Table 2: List of Control actions suggested by the OPF solution for Contingency TR 722-741.

\begin{tabular}{|c|c|c|c|c|c|c|}
\hline Control Type & $\begin{array}{c}\text { Bus } \\
\text { Number }\end{array}$ & Bus Name & $\begin{array}{c}\text { Initial } \\
\text { Value }\end{array}$ & $\begin{array}{c}\text { Deviat } \\
\text { ion }\end{array}$ & $\begin{array}{c}\text { Final } \\
\text { Value }\end{array}$ & Unit \\
\hline GE_P & 101 & CNUGH-1/2 & 47.0 & -7.9 & 39.1 & MW \\
\hline GE_P & 103 & CNUGH-03 & 29.4 & -7.1 & 22.2 & MW \\
\hline GE_P & 398 & $\begin{array}{c}\text { GER EM } \\
\text { CEA2 }\end{array}$ & 2.2 & -1.1 & 1.1 & MW \\
\hline GE_P & 496 & $\begin{array}{c}\text { SYUGD 33- } \\
41\end{array}$ & 8.8 & -1.6 & 7.2 & MW \\
\hline GE_P & 412 & $\begin{array}{c}\text { SYUGD 16- } \\
23\end{array}$ & 8.8 & -1.6 & 7.2 & MW \\
\hline GE_P & 404 & UGD-4/5/6 & 11.7 & 21.0 & 32.7 & MW \\
\hline GE_P & 411 & SYUGD 8-15 & 8.8 & -1.6 & 7.2 & MW \\
\hline GE_V & 101 & CNUGH-1/2 & 0.962 & 0.003 & 0.965 & p.u. \\
\hline GE_V & 103 & CNUGH-03 & 1.042 & -0.066 & 0.976 & p.u. \\
\hline GE_V & 398 & $\begin{array}{c}\text { GER EM } \\
\text { CEA2 }\end{array}$ & 1.037 & -0.055 & 0.982 & p.u. \\
\hline GE_V & 496 & $\begin{array}{c}\text { SYUGD 33- } \\
41\end{array}$ & 1.034 & -.0 .040 & 0.994 & p.u. \\
\hline GE_V & 412 & $\begin{array}{c}\text { SYUGD16- } \\
23\end{array}$ & 1.046 & -0.064 & 0.982 & p.u. \\
\hline GE_V & 404 & UGD-4/5/6 & 1.030 & -0.054 & 0.976 & p.u. \\
\hline GE_V & 411 & SYUGD 8-15 & 1.045 & -0.063 & 0.982 & p.u. \\
\hline AL_Q & 421 & $\begin{array}{c}\text { SANT TF } \\
13,8\end{array}$ & 0 & 1.793 & 1.793 & Mvar \\
\hline AL_Q & 441 & $\begin{array}{c}\text { SANTANA } \\
69\end{array}$ & 0 & 2.955 & 2.955 & Mvar \\
\hline
\end{tabular}

\begin{tabular}{|c|c|c|c|c|c|c|}
\hline AL_Q & 523 & SI TF1 13,8 & 0 & 2.508 & 2.508 & Mvar \\
\hline $\mathrm{AL} \_\mathrm{Q}$ & 524 & SI TF2 13,8 & 0 & 2.290 & 2.290 & Mvar \\
\hline AL_Q & 525 & MD TF1 13,8 & 0 & 1.636 & 1.636 & Mvar \\
\hline AL_Q & 621 & $\begin{array}{c}\text { EQT TF1 } \\
13,8\end{array}$ & 0 & 2.844 & 2.844 & Mvar \\
\hline AL_Q & 622 & $\begin{array}{c}\text { EQT TF3 } \\
13,8 \\
\end{array}$ & 0 & 2.580 & 2.580 & Mvar \\
\hline AL_Q & 721 & $\begin{array}{c}\text { EQT TF1 } \\
13,8\end{array}$ & 0 & 2.844 & 2.844 & Mvar \\
\hline AL_Q & 723 & $\begin{array}{c}\text { EQT TF3 } \\
13,8 \\
\end{array}$ & 0 & 2.580 & 2.580 & Mvar \\
\hline TAP & $141 / 199$ & - & 1.0000 & 0.0054 & 1.0054 & p.u. \\
\hline TAP & $321 / 351$ & - & 1.0500 & $\begin{array}{c}- \\
0.0114\end{array}$ & 1.0386 & p.u. \\
\hline TAP & \begin{tabular}{|c|}
$1021 / 10$ \\
41
\end{tabular} & - & 1.0000 & 0.0032 & 1.0032 & p.u. \\
\hline TAP & 921/941 & - & 1.0000 & 0.0011 & 1.0011 & p.u. \\
\hline TAP & $841 / 899$ & - & 1.0000 & $\begin{array}{c}- \\
0.0175\end{array}$ & 0.9825 & p.u. \\
\hline TAP & $441 / 497$ & - & 1.0500 & $\begin{array}{c}- \\
0.0468\end{array}$ & 1.0032 & p.u. \\
\hline TAP & $441 / 498$ & - & 1.0500 & $\begin{array}{c}- \\
0.0468\end{array}$ & 1.0032 & p.u. \\
\hline TAP & 723/741 & - & 1.0500 & $\begin{array}{c}- \\
0.0555 \\
\end{array}$ & 0.9445 & p.u. \\
\hline TAP & $721 / 741$ & - & 1.0000 & $\begin{array}{c}- \\
0.0154\end{array}$ & 0.9846 & p.u. \\
\hline TAP & $523 / 542$ & - & 1.0000 & 0.0232 & 1.0232 & p.u. \\
\hline TAP & $524 / 542$ & - & 1.0000 & $\begin{array}{c}- \\
0.0299 \\
\end{array}$ & 0.9701 & p.u. \\
\hline TAP & $525 / 542$ & - & 1.0000 & -0.229 & 0.9771 & p.u. \\
\hline TAP & $621 / 641$ & - & 1.0000 & 0.0303 & 1.0303 & p.u. \\
\hline TAP & $622 / 641$ & - & 1.0000 & 0.0217 & 1.0217 & p.u. \\
\hline
\end{tabular}

Source: Authors, (2019).

The voltages at all buses can be visualized graphically in figure 5. It is observed that the proposed control actions suggested by both control strategies have changed the voltage magnitudes at all buses to within the interval between $1.05 \mathrm{pu}$ and $0.95 \mathrm{pu}$, which is recommended for a secure operation.

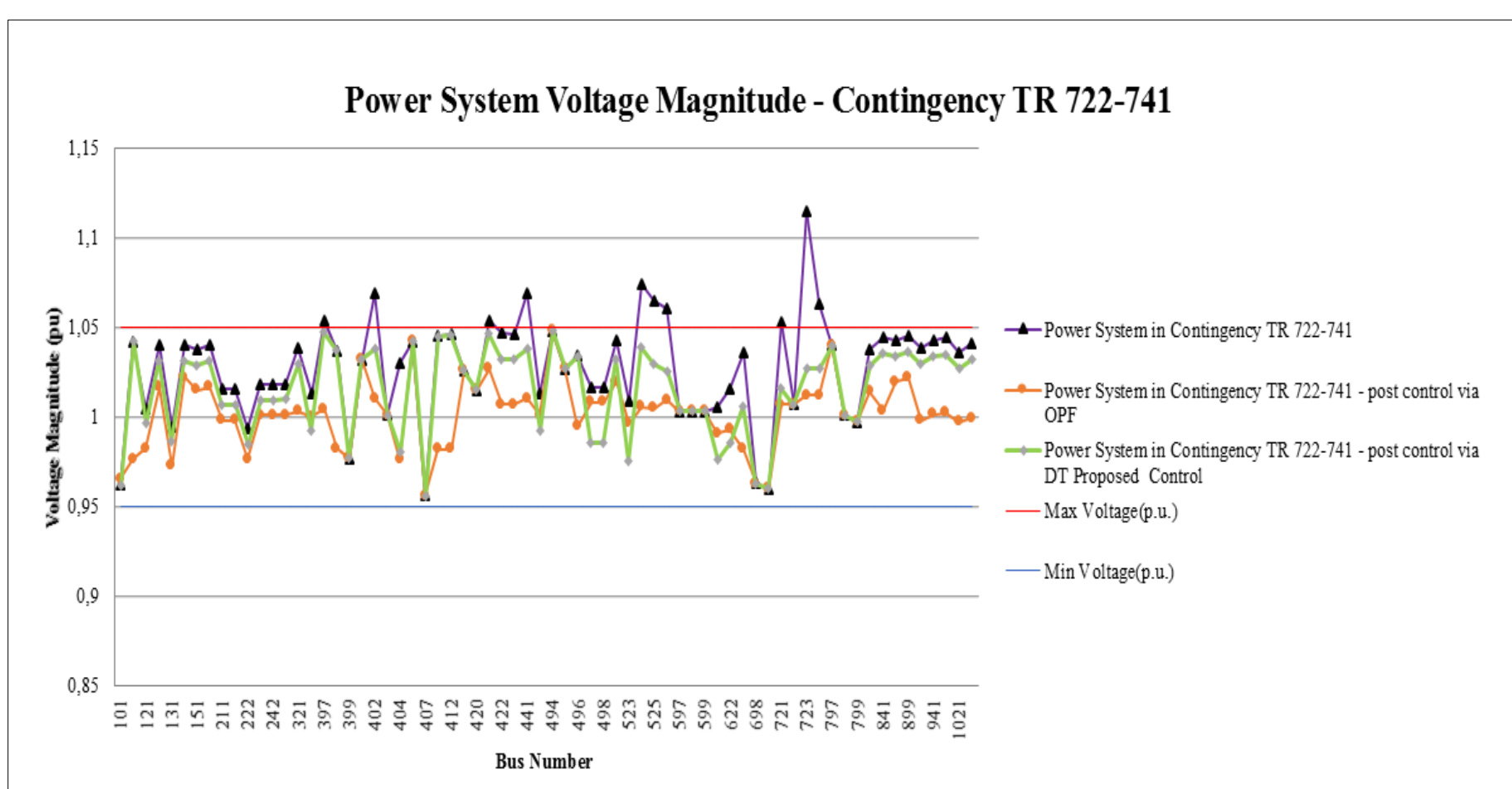

Figure 5: Bus Voltage Magnitude Profile for Contingency TR 722-741.

Source: Authors, (2019). 


\section{IV.2 CONTINGENCY 2: SHUTDOWN OF TRANSMISSION LINE 397-321}

In this contingency one of the three parallel transmission lines between buses 397-321 was disconnected. The decision tree generated for this case is shown in figure 6, indicating actions to be taken with respect to voltages at buses 621 and 721, which are load buses. These buses also have capacitor banks for local voltage control. For this contingency the DT suggested only one path which will lead the system to a security operational condition.

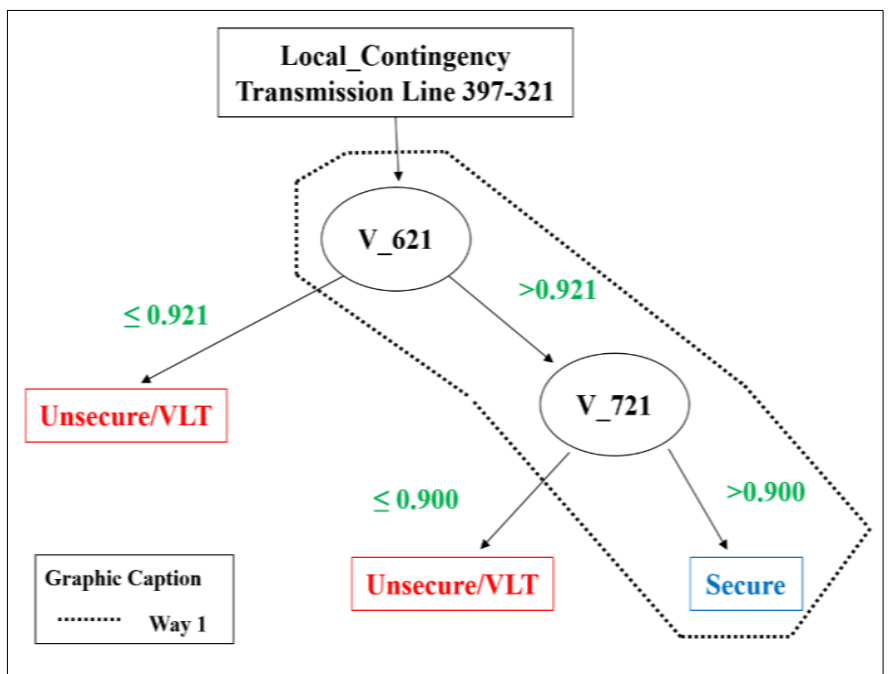

Figure 6: Decision Tree generated for Contingency TL 397-321. Source: Authors, (2019).

Following the decision tree and sensitivity analysis of the buses indicated by the decision tree solution, according to Table 3, a control action at bus 404 may be very effective in modifying voltage magnitudes at buses 621 and 721 . This control action is named control action 1 and corresponds to setting voltage at bus 404 to $1 \mathrm{pu}$.

Table 3: Sensibility Factors for Contingency TL 397-321.

\begin{tabular}{|c|c|c|c|c|}
\hline Dependent Variable & \multicolumn{4}{|c|}{ Control Variable } \\
\hline $\begin{array}{c}\text { Bus Voltage } \\
\text { Specified by } \\
\text { Decision Tree }\end{array}$ & $\begin{array}{c}\text { Bus } \\
\text { Number }\end{array}$ & $\begin{array}{c}\text { Sensitivity } \\
\text { Factor }\end{array}$ & $\begin{array}{c}\text { Taps } \\
\text { From-To }\end{array}$ & $\begin{array}{c}\text { Sensitivity } \\
\text { Factor }\end{array}$ \\
\hline V_621 & 404 & 0,636 & $622 / 641$ & 1,075 \\
\cline { 2 - 5 } & 101 & 0,216 & $441 / 497$ & 0,367 \\
\hline V_721 & 404 & 0,652 & $721 / 741$ & 1,185 \\
\cline { 2 - 5 } & 101 & 0,221 & $441 / 497$ & 0,376 \\
\hline
\end{tabular}

Source: Authors, (2019).

With this control action, six of the seven buses that were outside the voltage limits, had their voltages returned within the limits, and only bus 723 voltage was violated, its magnitude being $1.073 \mathrm{pu}$.

The control action implemented at bus 404 was very effective, but did not eliminate all voltage violations. According to the sensitivity analysis shown in Table 3, other control actions can be tested to eliminate the voltage violation at bus 723 , as for example, tap changes at transformers 622-641 and 721-741.

However, it is also known by the operation staff that bus 723 with over voltage of 1.084 pu has two capacitor banks in operation, and an evident solution is total or partial shutdown of theses banks. So the complementary control action, called control action 2, was:

\section{Capacitor banks shutdown at bus 723 .}

With this complementary control action all bus voltages have returned to within the recommended operation limits. So, the proposed control actions are the performed control action 1 and control action 2 .

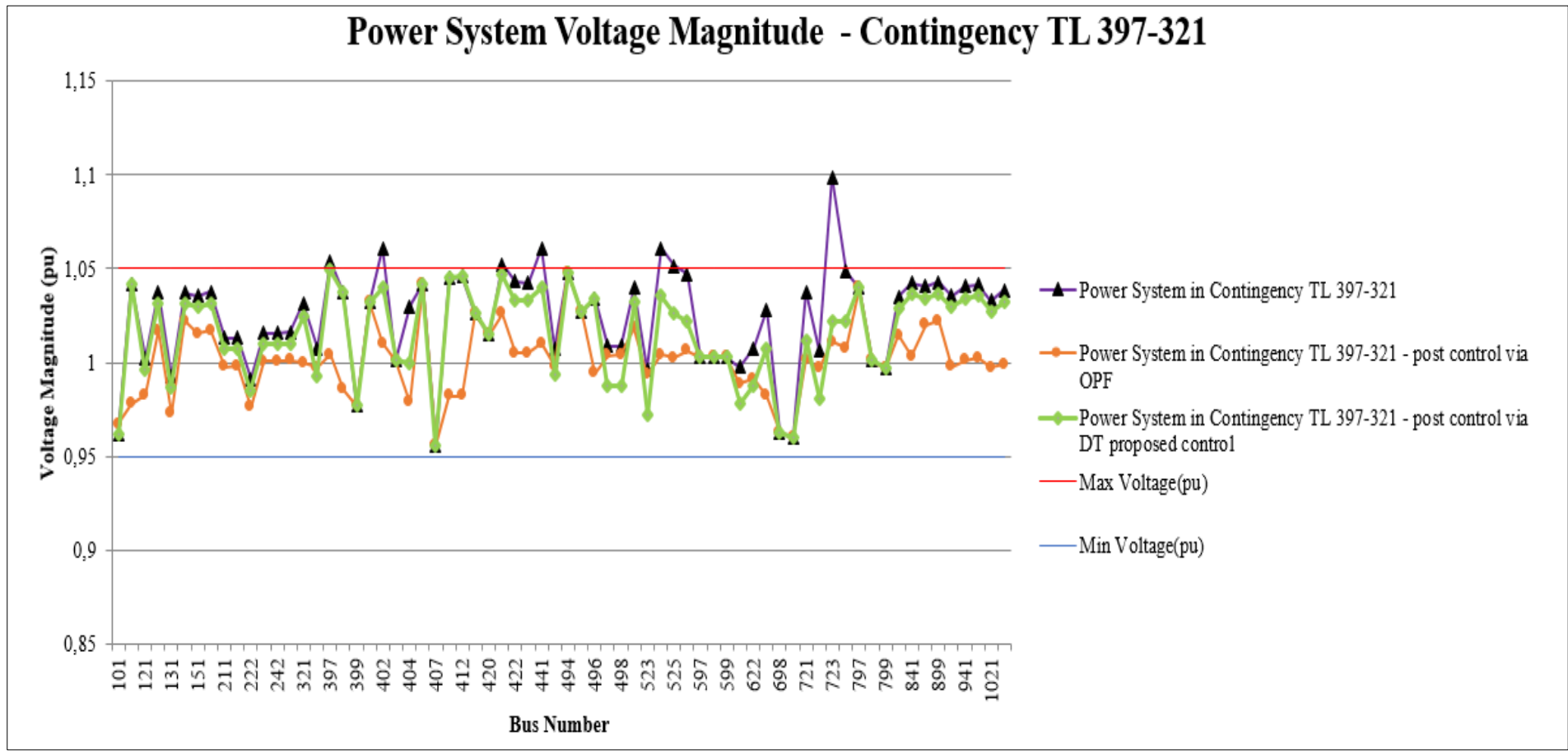

Figure 7: Bus Voltage Magnitude Profile for Contingency TL 397-321.

Source: Authors, (2019).

Table 4 shows the controls performed through the OPF procedure, showing all 39 control actions performed in the optimization process. 
Nogueira et al., ITEGAM-JETIA. Vol. 06, № 21, pp 04-12. February, 2020.

Table 4: List of Control actions sed in the OPF Optimization for Contingency TL 397-321.

\begin{tabular}{|c|c|c|c|c|c|c|}
\hline $\begin{array}{c}\text { Control } \\
\text { Type }\end{array}$ & $\begin{array}{c}\text { Bar } \\
\text { Number }\end{array}$ & Bar Name & \begin{tabular}{|l|} 
Initial \\
Value
\end{tabular} & Deviation & $\begin{array}{l}\text { Final } \\
\text { Value }\end{array}$ & Unit \\
\hline GE_P & 101 & CNUGH-1/2 & 47.0 & -5.6 & 41.4 & MW \\
\hline GE_P & 103 & CNUGH-03 & 29.4 & -5.4 & 24.0 & MW \\
\hline GE_P & 398 & $\begin{array}{c}\text { GER EM } \\
\text { CEA2 }\end{array}$ & 2.2 & -1.0 & 1.2 & MW \\
\hline GE_P & 496 & SYUGD 33-41 & 8.8 & -0.9 & 9.7 & MW \\
\hline GE_P & 412 & SYUGD 16-23 & 8.8 & -0.6 & 8.3 & MW \\
\hline GE_P & 404 & UGD-4/5/6 & 24.2 & 14.6 & 38.7 & MW \\
\hline GE_P & 411 & SYUGD 8-15 & 8.8 & -0.6 & 8.3 & MW \\
\hline GE_V & 101 & CNUGH-1/2 & 0.962 & 0.005 & 0.967 & p.u. \\
\hline GE_V & 103 & CNUGH-03 & 1.042 & -0.064 & 0.978 & p.u. \\
\hline GE_V & 398 & $\begin{array}{c}\text { GER EM } \\
\text { CEA2 }\end{array}$ & 1.037 & -0.051 & 0.986 & p.u. \\
\hline GE_V & 496 & SYUGD 33-41 & 1.034 & -0.040 & 0.994 & p.u. \\
\hline GE_V & 412 & SYUGD16-23 & 1.046 & -0.064 & 0.982 & p.u. \\
\hline GE_V & 404 & UGD-4/5/6 & 1.030 & -0.051 & 0.979 & p.u. \\
\hline GE_V & 411 & SYUGD 8-15 & 1.045 & -0.063 & 0.982 & p.u. \\
\hline AL_Q & 421 & SANT TF 13,8 & 0 & 1.962 & 1.962 & Mvar \\
\hline AL_Q & 441 & SANTANA 69 & 0 & 3.346 & 3.346 & Mvar \\
\hline AL_Q & 523 & SI TF1 13,8 & 0 & 2.728 & 2.728 & Mvar \\
\hline AL_Q & 524 & SI TF2 13,8 & 0 & 2.515 & 2.515 & Mvar \\
\hline AL_Q & 525 & SI TF3 13,8 & 0 & 2.544 & 2.544 & Mvar \\
\hline AL_Q & 621 & MD TF1 13,8 & 0 & 1.725 & 1.725 & Mvar \\
\hline AL_Q & 622 & MD TF2 13,8 & 0 & 1.702 & 1.702 & Mvar \\
\hline AL_Q & 721 & EQT TF1 13,8 & 0 & 3.248 & 3.248 & Mvar \\
\hline AL_Q & 722 & EQT TF2 13,8 & 0 & 3.477 & 3.477 & Mvar \\
\hline AL_Q & 723 & EQT TF3 13,8 & 0 & 2.915 & 2.915 & Mvar \\
\hline TAP & $141 / 199$ & - & 1.0000 & 0.0049 & 1.0049 & p.u. \\
\hline TAP & $321 / 351$ & - & 1.0500 & $\begin{array}{c}- \\
0.0196\end{array}$ & 1.0304 & p.u. \\
\hline TAP & $1021 / 1041$ & - & 1.0000 & 0.0031 & 1.0031 & p.u. \\
\hline TAP & $921 / 941$ & - & 1.0000 & 0.0010 & 1.0010 & p.u. \\
\hline TAP & $841 / 899$ & - & 1.0000 & $\begin{array}{c}- \\
0.0181 \\
\end{array}$ & 0.9819 & p.u. \\
\hline TAP & $441 / 497$ & - & 1.0500 & $\begin{array}{c}- \\
0.0429 \\
\end{array}$ & 1.0071 & p.u. \\
\hline TAP & $441 / 498$ & - & 1.0500 & $\begin{array}{c}- \\
0.0430\end{array}$ & 1.0070 & p.u. \\
\hline TAP & $723 / 741$ & - & 1.0500 & $\begin{array}{c}- \\
0.0544\end{array}$ & 0.9456 & p.u. \\
\hline TAP & $722 / 741$ & - & 1.0000 & 0.0082 & 1.0082 & p.u. \\
\hline TAP & $523 / 542$ & - & 1.0000 & 0.0211 & 1.0211 & p.u. \\
\hline TAP & $524 / 542$ & - & 1.0000 & $\begin{array}{c}- \\
0.0301 \\
\end{array}$ & 0.9699 & p.u. \\
\hline TAP & $525 / 542$ & - & 1.0000 & $\begin{array}{c}- \\
0.0235\end{array}$ & 0.9765 & p.u. \\
\hline TAP & $621 / 641$ & - & 1.0000 & 0.0274 & 1.0274 & p.u. \\
\hline TAP & $622 / 641$ & - & 1.0000 & 0.0191 & 1.0191 & p.u. \\
\hline TAP & $721 / 741$ & - & 1.0000 & $\begin{array}{c}- \\
0.0168 \\
\end{array}$ & 0.9832 & p.u. \\
\hline
\end{tabular}

Source: Authors, (2019).

Figure 7 presents graphically the obtained solutions for solving contingency 2 voltage limits violations calculated by both solution techniques, that is, Decision Tree approach and OPF approach. Both solutions guarantee the power system is maintained operating in a secure state, but in terms of practical implementation the DT solution is more viable because only a few control actions are needed to be taken

\section{CONCLUSIONS}

The results obtained by both corrective control techniques showed that these techniques are efficient in ensuring the power system secure operation. However, the big difference between both lies in the practical aspects of implementing control actions in realtime operation. Regarding this aspect, the DT technique is more attractive because, in general, the number of required control actions to maintain the power system security is much lower than the number of control actions required by the OPF approach.
Besides that, DT also presents an intuitive interface for the operator, precisely identifying the electrical variables on which control actions should be exercised to return the system operation to a secure condition. In general, both methodologies are complementary tools in supporting the power system security, for both real-time operation or as operation planning tools.

\section{AKNOWLEDGMENTS}

Thanks to PPGEE - UFPA and CAPES for their academic, structural, and financial support.

\section{REFERENCES}

[1] Sharifzadeh, H.; Amjady, N.; Zareipour, H., Multi-period stochastic security-constrained OPF considering the uncertainty sources of wind power, load demand and equipment unavailability, Electric Power Systems Research, Volume 146, May 2017, Pages 33-42.

[2] Liu C.; Sun K.; Rather Z.; Chen Z.; LethBak C.; Thøgersen P.; Lund P. A Systematic Approach for Dynamic Security Assessment and the Corresponding Preventive Control Scheme Based on Decision Trees. IEEE Transactions on Power Systems, Vol. 29, No. 2, March, 2014.

[3] Monticelli, A.J. Power Flow in Electric Network. Edgar Blucher Limited, First edition, São Paulo, 1983.

[4] Rodrigues, B.G.D., Using Decision Trees for Assessing Real Time Static Security in Electric Power Systems. Master Dissertation, Federal University of Pará- UFPA ,2014.

[5] CEPEL- Electricity Studies and Research Center: Optimal Power Flow Program -FLUPOT - User's Guide vs. 07.05.01. CEPEL, Brazil, 2016.

[6] CEPEL- Electricity Studies and Research Center: Electric Networks Analysis Program - ANAREDE.- User's Guide vs. 09.07.02. CEPEL, Brazil, 2011

[7] Oliveira, W.D. Power Systems Dynamic Security Assessment Focusing on Transient Stability Using Decision Trees. Electric Engineering Course Final Report. Federal University of Pará UFPA, 2011.

[8] Borlea, I.; Kilyeni, S.; Lustrea, B. Knowledge Based Systemfor Power System Static Security Assessment. IEEE Transactions on Power Systems. EUROCON 2005 - The International COnference on "Computer as a Tool". November, 2005.

[9] Jiongcong, C.; Liang, G.; Zexiang, C.A.I.; Chunchao, H.U.; Yan, X.U.; Fengji, L.U.O.; Junhua, Z.H.A.O. Impact analysis of false data injection attacks on power system static security assessment. J. Mod. Power Syst. Clean Energy 2016, 4, 496-505.

[10] Li, Y.; Li, Y.; Sun, Ya. Online Static Security Assesment of Power Systems Based on Lasso Algorithm. Aplied Sciences. MDPI. 2018, August.

[11] Kundur, P. Power System Stability and Control. EPRI, 1994.

[12] Beyranvand, P.; Genc,V.M.I.; Ataltepe, Z. Multi-label learning for the online transient stability assessment of electric power 2 systems. Turk J Elec Eng \& Comp Sci. 2018, September.

[13] Wehenkel, L.A. Automatic Learning Techniques in Power Systems, Kluwer, Norwell, MA, 1998. 
[14] Shi, L. B.; Chang, N. C.; Lan, Z.; Zhao, D. P.; Zhou, H. F.; Tam, P. T. C.; ... Wu, F. F. Implementation of a Power System Dynamic Security Assessment and Early Warning System. 2007 IEEE Power Engineering Society General Meeting.

[15] Dy Liacco, T. E. Real-Time Computer Control of Power Systems. Proceedings of the IEEE, Vol. 62, no 7. July, 1974.

[16] WU, F. F.; MOSLEHI, K.; BOSE, A. Power System Control Centers: Past, Present, and Future. Proceedings of the IEEE, Vol. 93, No11, p.1890-1908, November, 2005

[17] Camilo, C.O.; Silva, J.C. Data Mining: Concepts, Tasks, Methods and Tools. Technical Report, Federal University of Goias - UFG, 2009.

[18] Powell, L. "Power System Load Flow Analysis", New York: McGraw-Hill, 2005, p. 63.

[19] Schiochet, A.F. Multi-objective Optimal Power Flow: An Approach Using a Parameterization Strategy. Master Dissertation, Federal University of Santa Catarina -UFSC, 2006.

[20] Cain, M.B., O’neil, R.P., Castillo, A., History of Optimal Power Flow and Formulations - Optimal Power Flow. Paper 1.Tech.Rep., US FERC, Dec. 2012. 